\title{
On the likelihood of using Mobility-as-a-Service: a case study on innovative mobility services among residents in the Netherlands
}

\author{
Tiago Fioreze*, Martijn de Gruijter, Karst Geurs \\ Faculty of Engineering Technology, Centre for Transport Studies, University of Twente, \\ P.O. Box 217, 7500 AE, Enschede, the Netherlands
}

\begin{abstract}
This research study aims at providing new insights regarding attitudes among residents towards the introduction of Mobility-asa-Service (MaaS). We were especially interested in finding out how likely residents would be willing to use MaaS when introduced in their place of residence. The study involved a quantitative survey and focus group interviews with residents in the Paleiskwartier district, in the city of 's-Hertogenbosch, the Netherlands. Our results show that positive attitudes towards MaaS are the most important factors for the intention to use MaaS, whereas socio-economic characteristics seem not to play a role. Moreover, our results also indicate that most residents are more likely to not use MaaS in the long run, but a considerable amount of them would be interested in trying it out, at least. Equally important, the introduction of MaaS pilots may experience a greater receptivity among residents who do not see car ownership and usage as very important aspects, who regularly use public transport and who are mostly concerned with the environment and with a healthy commuting lifestyle. Conversely, people who use the car on a daily basis and regard car ownership as a very important aspect are far less receptive to MaaS pilots. Therefore, the sole idea of MaaS as an environmentally friendly alternative to make car ownership superfluous may potentially be inefficient against avid car users.
\end{abstract}

Keywords: survey, focus group, residents, Mobility-as-a-Service, likelihood of use.

\section{Introduction}

The growing pressure on urban passenger transport systems has increased the demand for new and innovative mobility solutions to increase the efficiency of those systems. The shift from owning vehicles to sharing them could potentially tackle this challenge. In combination with conventional public transport, shared modes could serve as a substitute to privately owned vehicles (Kamargianni et al., 2016). However, the complexity of using shared modes and transit offered by different companies - each having different payment methods and subscriptions discourages many people from taking advantage of them. The digital integration among several transport options could diminish the complexity for travellers to use these options, though.

As a matter of fact, the development of new areas in the ICT research landscape has brought new opportunities for the development of innovative mobility solutions. Uber, for instance, revolutionised the way that rides were shared by introducing real-time peer-to-peer ride-sharing through a smartphone app. Several years after its launch, Uber is present in more than 500 cities with more than 40 million monthly users (Kokalitcheva, 2016). A more recent concept arising in the field of mobility is Mobility-as-a-Service (a.k.a. MaaS). Even though there is no clear agreement on one definition of MaaS (Smith et al., 2018),

\footnotetext{
${ }^{*}$ Corresponding author.

Email address: t.fioreze@utwente.nl (Tiago Fioreze)
}

it can be seen as a concept for the integration of different types of mobility, such as shared rides, shared bikes or shared cars and public transit into a single interface (commonly a smartphone app or website). As stated by Kamargianni et al. (2016), the concept of MaaS "stands for buying mobility services based on consumer needs instead of buying the means of mobility".

The research study presented in this paper is part of the Dutch Innovatieprogramma Mobiele Stad consortium (IMS, 2019), which conducts practical experiments aimed at concrete innovations for the integration of mobility, technology and space in different regions of the Netherlands. From June 2019 on, a sixmonth Maas pilot will be held in a highly dense neighbourhood, namely the Paleiskwartier, which is a district belonging to the municipality of 's-Hertogenbosch, colloquially known as Den Bosch, in the southern part of the Netherlands (Figure 1).

The aim of this pilot study is to examine if MaaS can reduce the demand for car traffic and car parking, and, as a result, contribute to urban developments (e.g., further densification of areas around transport stations). In other words, if MaaS can help reduce demand for on- and off-street parking, then trip generation and parking standards could be lowered and built-up areas can potentially be densified. The Paleiskwartier area has particularly been chosen as it is a relatively densely populated railway station area, which is still being developed and local stakeholders aim to reduce car use and support mobility innovations. The Paleiskwartier district is an interesting case study area to examine the potential uptake of MaaS as residents living close to an 


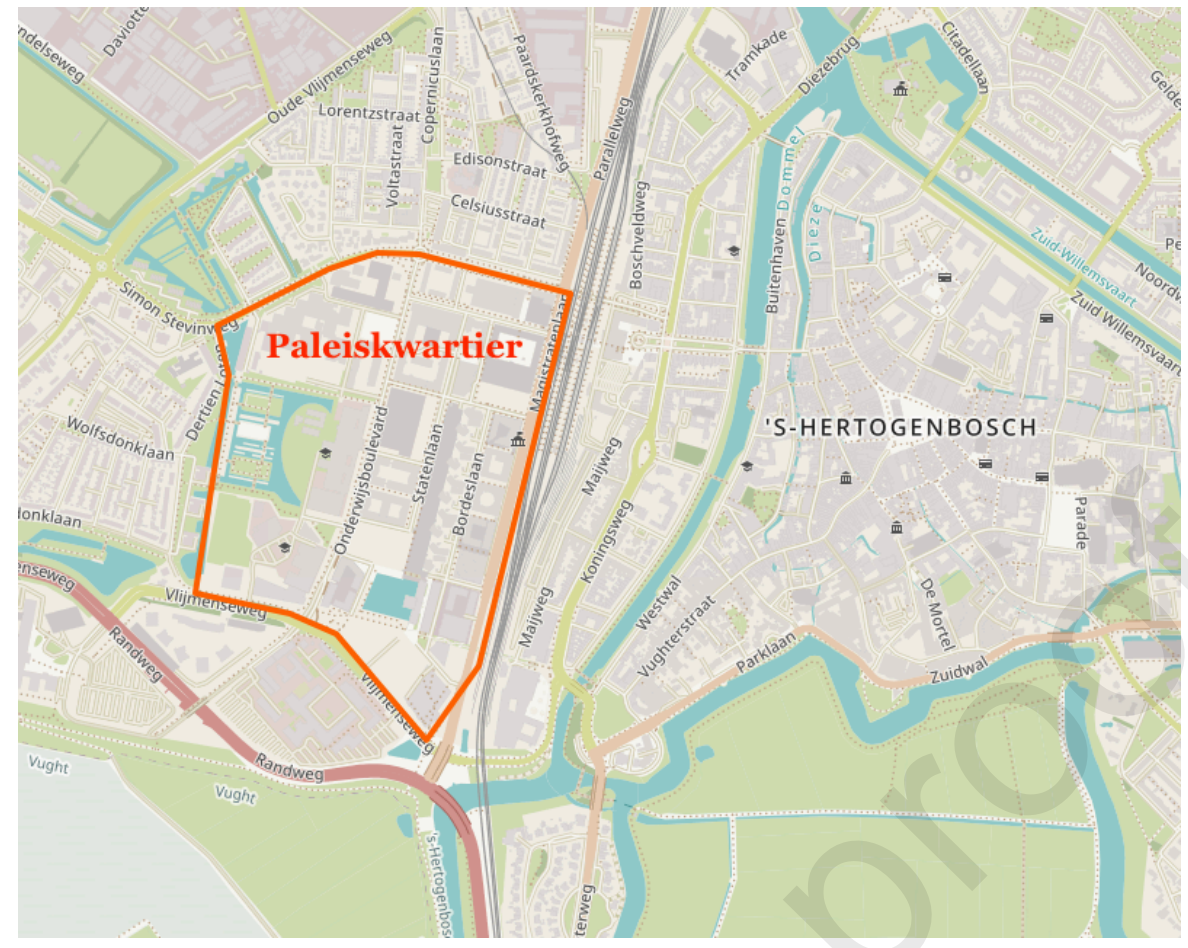

Figure 1: The location of the Paleiskwartier district in the city of 's-Hertogenbosch.

intercity train station are expected to be familiar with public transport and app-based mobility services.

All in all, this research paper aims at: 1) quantifying the current travel behaviour of residents in the Paleiskwartier district; 2) investigating their views and attitudes towards the introduction of a MaaS platform in their place of residence; 3) determining what factors influence their intention to use MaaS, and 4) identifying 'Paleiskwartier personas' for both commercial and research purposes on the intention to use MaaS.

The remainder of this paper is structured as follows. Section 2 presents a literature review on Mobility-as-a-Service in densely populated areas. Following that, Section 3 describes how our research study was conducted and how data was analysed. Next, Section 4 shows the results of the several analyses performed. Finally, we close this paper in Section 5, where we discuss our results and the practical implications of our study. This section also presents the limitations of our research as well as some recommendations for future research directions.

\section{Literature review}

The concept of Mobility-as-a-Service (MaaS) has increasingly been receiving attention in academic literature. MaaS was first coined in Finland and became a hot topic after the ITS Europe 2014 Congress in Helsinki (Hietanen, 2014). MaaS could be described as a mobility distribution model in which users' transportation needs are met over one interface and are offered by a service provider. However, this definition is not exhaustive, since there is no clear agreement on one definition of MaaS (Smith et al., 2018). However, MaaS is frequently described by different authors (Kamargianni et al., 2015) (Kamargianni et al.,
2016) (Sochor et al., 2017) (Durand et al., 2018) (Jittrapirom et al., 2017) in terms of integration of several transport options (public transport, taxi, car-sharing, ride-sharing, bike-sharing, car-rental) in one platform with integrated ticket and payment in monthly payments and/or pay-as-you-go.

Nowadays, several MaaS initiatives are currently operational, most of them in major cities across Europe, as summarised by Durand et al. (2018). Of the already concluded MaaS initiatives, one of the largest MaaS pilots was conducted in Göthenburg, Sweden from 2013 till 2014, called UbiGo. This pilot has specifically looked at users motives and barriers to take up MaaS. A group of participants $(n=164)$ has been introduced with the new mobility service, which included public transport, car-sharing, bike-sharing, and taxi services. An expost analysis among the participants showed that UbiGo users had a higher than average interest in technology, and the adults in the household were likely innovators (Sochor et al., 2014). The initial motivation to participate in the pilot was mainly curiosity $(63 \%)$, but once the pilot was concluded the main motive to start using the UbiGo platform became flexibility (22\%). Deterrents to not take part in the pilot were mainly economic reasons (too expensive), and other travel interests (e.g., cycling and/or walking). Furthermore, $16 \%$ of the non-users, that is who did express interest, but did not sign up, were too busy to learn more about the initiative in Göthenburg. As a conclusion, Strömberg et al. (2018) state that it is difficult to provide general statements about behavioural changes by implementing new travel services. They do say however that the initial motivation on a household level is very important.

Another concluded MaaS initiative was the MaaS pilot conducted in Vienna, Austria from 2014 till 2015, called Smile. 
This pilot started with approximately 1,000 participants, but only 200 participants filled in an ex-post questionnaire (Karlsson et al., 2017). Half of the participants in the Smile pilot were between 20 and 40 years old and the majority of the respondents (79\%) was male. Car possession was moderate $-60 \%$ of the respondents owned a car - and three-quarter (77\%) possessed a bike. The Smile application was not used very frequently. Only $30 \%$ of the respondents used the application on a weekly basis, while $6 \%$ of them used it on a daily basis. The application was predominantly used for non-routine trips, such as leisure trips. Public transport use was high among Smile users. Almost 90\% of the respondents used transit on a regular basis: daily or several times per week. Equally important, $50 \%$ of the respondents indicated that their travel pattern changed. For example, 50\% indicated that they used transit more often and $20 \%$ indicate that they used less their private car.

All in all, the results of the UbiGo and Smile pilots seem to indicate that the introduction of MaaS contributes to higher use of multimodal trips, higher use of transit and lower use of the private car. MaaS provides a transparent insight in multimodal travel alternatives, which makes it easier for the consumer to use, for instance, public transport or shared car.

In the Netherlands, similar integrated-mobility schemes (e.g., NS Business Card, MobilityMixx, amongst others) have been made available across the country since 2013 for business travellers. These travellers have access to a variety of modes including shared modes, public transport, and taxis. To date, these integrated-mobility schemes do not include ride-sharing as a mobility option, though. This situation will change soon, given that the Dutch Ministry of Infrastructure and Water management plans to experiment with several MaaS pilots in 2019. One of these pilots is going to be conducted in the Paleiskwartier. The ex-ante evaluation conducted in our research study, which precedes this pilot, is the main contribution of this paper.

\section{Methods}

In this section, the methodology used to conduct our survey of residents and focus group interviews will be presented, followed by an overview of the data analysis used in this paper.

\subsection{Population of interest}

The Paleiskwartier district has a population of 3,130 inhabitants (Dutch Central Bureau of Statistics, 2019) and it has been under development since the end of the $20^{\text {th }}$ century. It is designed as a mixed living and working area, having, for example, apartment complexes, education institutes, restaurants, companies, among other facilities. Equally relevant, the Paleiskwartier is located next to the central railway station for the city of 's-Hertogenbosch and is also close to important national motorways.

\subsection{Questionnaire}

A mix of paper-based and online questionnaires was employed to collect data. In total, approximately 2,000 envelopes were distributed house-to-house in the Paleiskwartier. Each household received an envelope containing a printed copy of the questionnaire, a letter explaining the rationale for the study and a self-addressed pre-paid return envelope. The respondent could then either fill in the paper-based questionnaire and return to us or use the QR code or Web link (provided in the explanatory letter) to access our on-line survey. A prize draw was used to stimulate the respondents to complete the survey. Responses were collected for approximately 4 weeks from October $2^{\text {nd }}$ till October $28^{\text {th }}$, 2018. Finally, it took approximately 10 minutes for the participants to complete the questionnaire.

The questionnaire consisted of a mix of single-choice and multiple-choice types of questions. Regarding the former, it consisted of questions with ratings (5-point Likert-type scale) or nominal scales. In addition, a mock-up containing screenshots of a smartphone app was used for the sake of aiding respondents to better comprehend what the MaaS app could look like. As such, the survey design was a combination of revealedpreference and stated-preference questions. We used revealedpreference questions for the sake of segmentation since we were interested in finding out whether different segments of residents show different attitudes towards the likelihood of using MaaS when introduced in the Paleiskwartier.

\subsection{Focus group}

A focus group session was also organised, following the online questionnaire, in January 2019 among a select group of survey participants. The goal of this session was to find out more about motivations (as well as potential deterrents) for participants interested in taking up MaaS. Monetary compensation was offered to participants in exchange for their participation. Moreover, a list of questions and key points were prepared beforehand in order to have a productive conversation with the participants. Lastly, the conversations in the focus group were recorded by means of audiovisual recording.

The session lasted for approximately 2 hours and was divided into 2 blocks with a short break of 15 minutes in between. The first block comprised of allowing the participants to get to know each other as well as in investigating their opinions and attitudes towards traditional modes of transport. After the break, the MaaS concept was explained to the participants by means of mock-ups and a short movie (about 2 minutes long). Hereafter, the participants expressed their opinions and attitudes about the introduction of MaaS in the Paleiskwartier.

\subsection{Data analysis}

Data were analysed with SPSS Statistics (version 25) by using descriptive, exploratory and regression analysis techniques. A statistical approach was firstly based on the distribution of responses. Next, proportions were compared using bivariate association analysis. Following that, ordinal regression was used to estimate the association between all predictors from the bivariate analysis that correlate statistically significantly with the likelihood of using MaaS. Finally, two-step cluster analysis was used to distinguish different personas (i.e., clusters) among respondents with respect to their intention of using MaaS. 


\section{Results}

First, we present an overview of the participants who took part in our study. Then, we show some relevant descriptive statistics used in our analysis. Next, the analysis of the correlations between different categorical variables is presented and discussed. Following, we introduce an ordinal regression model to predict the likelihood of using MaaS. After that, we present the personas resulting from our cluster analysis. Finally, we present the results of our focus group interviews.

\subsection{Participants}

Of the approximately 2,000 households who received our envelopes, 568 completed the survey yielding a response rate of $28 \%$. Equally relevant, of the 568 respondents, $347(61 \%)$ filled in the survey on paper whereas 221 (39\%) took part in the on-line survey. The demographics of the participants (Table 1) were rather disproportional to the population in the Paleiskwartier, though (Dutch Central Bureau of Statistics, 2019). A larger than expected proportion of participants are older than 45 years old. Young individuals (15 to 24 years old) are, for example, underrepresented in our sample. In addition, the population distribution by household size is also disproportional. Our sample consists mostly of residents who live with one companion whereas more than half (55.8\%) of the population in the Paleiskwartier live alone. Moreover, when comparing the average household size of the population in the Paleiskwartier district with the other districts in 's-Hertogenbosch, we observed that households in the Paleiskwartier are significantly smaller $(\bar{x}=1.69)$ than the average household in 's-Hertogenbosch $(\bar{x}=3.13), \mathrm{t}=-$ 25.881 (df=3427), $\mathrm{p}=0.000$.

\subsection{Univariate analysis}

We present now our survey data with summary descriptions of single variables. The major characteristic of a single variable that we are interested in is its frequency distribution.

\subsubsection{General travel behaviour}

The percentage of participants using a particular mean of transport is presented in Figure 2. Driving a car without passengers ( $\mathrm{Car}(1))$ is mostly done by the respondents on a daily basis $(40 \pm 4 \%)$, followed then by the daily use of the bicycle $(27 \pm 4 \%)$ and train $(17 \pm 4 \%)$. The use of bus occurs sporadically $(44 \pm 4 \%)$, at best. Moreover, respondents seem to offer a ride to others $(\mathrm{Car}(2))$ on a weekly basis $(37 \pm 4 \%)$, whereas taking a ride $(\operatorname{Car}(3))$ occurs mostly on a monthly basis $(33 \pm 4 \%)$.

Table 1: The demographics of the participants in our survey.

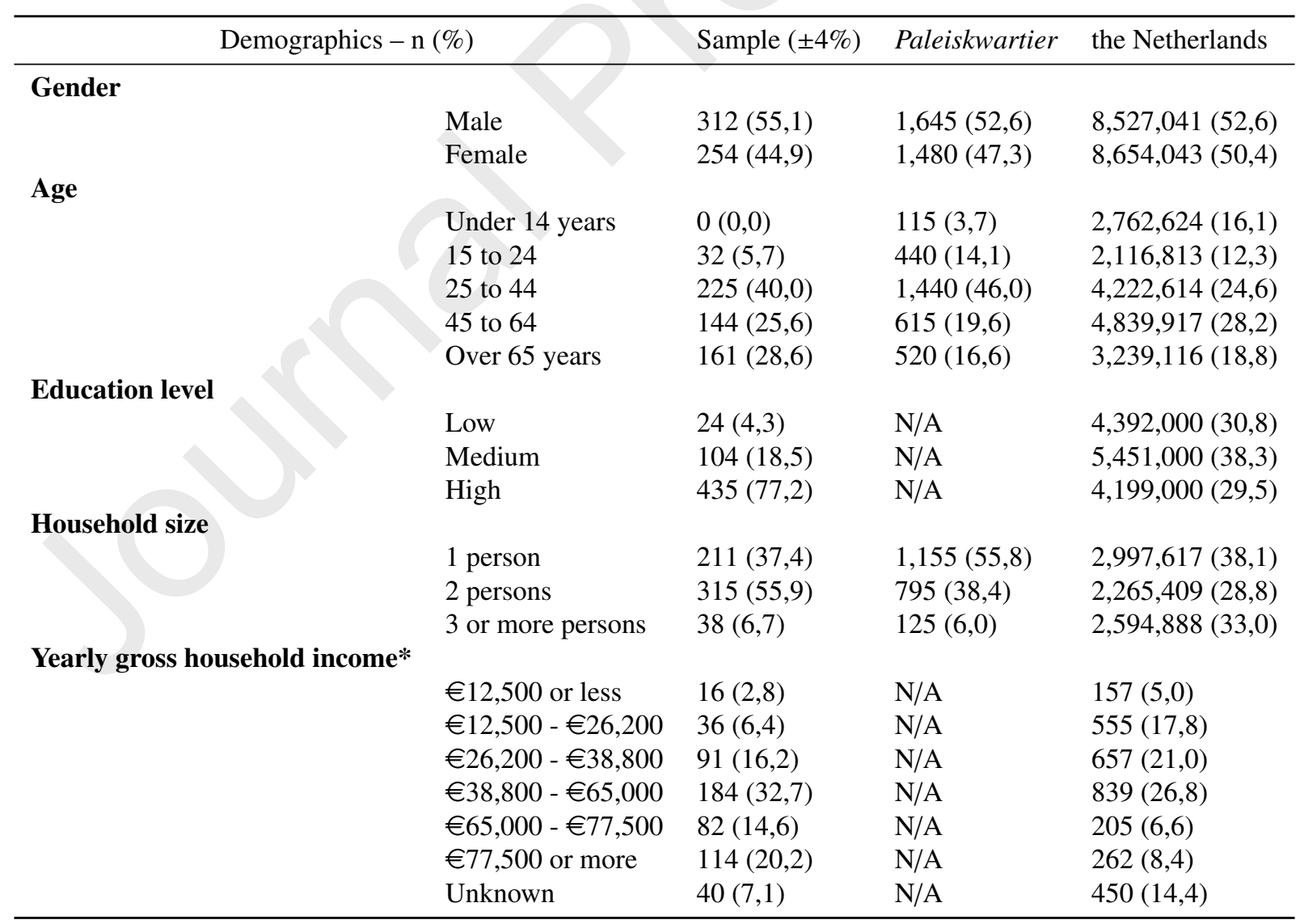

Note 1. The household income distribution for the Netherlands is based on the Netherlands Mobility Panel (Hoogendoorn-Lanser et al., 2015) Note 2. Cells containing 'N/A' mean (information) not available. 
We have also asked the respondents about how often they use mopeds/scooters, which resulted in the great majority of them $(96 \pm 4 \%)$ reporting as almost never using it.

How often do you use these means of transport?

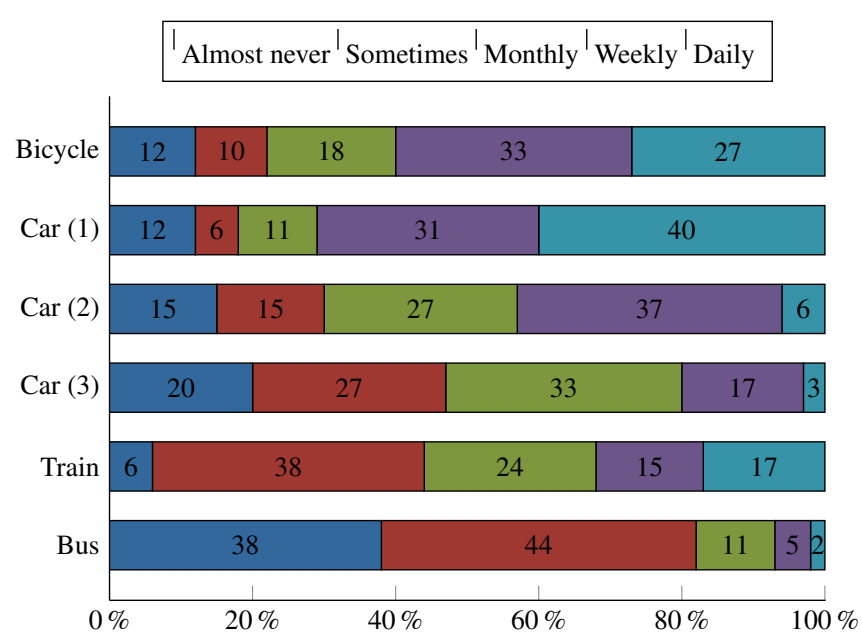

Figure 2: Frequency of usage per mean of transport.

Based on the Dutch National Travel Survey (Dutch Central Bureau of Statistics, 2015), we have observed that residents in the Paleiskwartier daily use the train more frequently than residents in other densely populated areas in the Netherlands: $17 \%$ vs $7 \%$, respectively. A higher frequency has also been observed in comparison with the other districts in 'sHertogenbosch. Valuable to note that concerning car ownership, it has been observed that residents in the Paleiskwartier have significantly lower car ownership rates per household $(\bar{x}=$ 0.93 cars/household) than the population of 's-Hertogenbosch $(\bar{x}=1.34$ cars/household $), \mathrm{t}(2655)=-12.575, \mathrm{p}=0.000$.

The intention to use the train for different trip purposes is also higher in the Paleiskwartier than in other densely populated areas in the Netherlands (Hoogendoorn-Lanser et al., 2015), as shown in Table 2.

\begin{tabular}{|c||c|c|}
\hline \multirow{2}{*}{ Trip purpose } & \multicolumn{2}{|c|}{ Mean of transport: train (\%) } \\
& Paleiskwartier & Other areas \\
\hline Travel to work & 25 & 4 \\
\hline Make a business trip & 41 & 14 \\
\hline Travel to school & 28 & 9 \\
\hline Go shopping & 4 & 3 \\
\hline Go to visit someone & 11 & 2 \\
\hline Go out socially & 44 & 13 \\
\hline
\end{tabular}

Table 2: Frequency distribution per trip purpose for using the train as the preferred mean of transport.

Participants were asked here about which mean of transport they prefer as their main transport mode for a certain trip purpose. It is worth mentioning that we observed higher preference for using the train among residents with higher levels of education, $\chi^{2}(8)=34.23, \mathrm{p}<0.001$, and with higher yearly household income, $\chi^{2}(4)=11.54, \mathrm{p}=0.021$. We believe that the proximity of the Paleiskwartier district to the central railway station for the city of 's-Hertogenbosch also plays a major role in the preference for the train among Paleiskwartier residents.

We have also enquired the respondents about how often they use a route planner (e.g., Google Maps) on their smartphone (Figure 3). Most respondents (32 $\pm 4 \%$ ) make use of route planners on a monthly basis.

How often do you use a route planner on your smartphone?

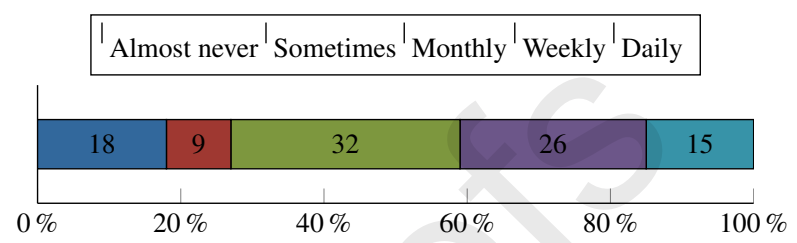

Figure 3: Frequency of usage of route planners among participants.

Last but not least, when asked to rank a set of aspects when choosing means of transport (Figure 4), participants chose "I want to save travel time" as a very important aspect for choosing a specific mean of transport $(32 \pm 4 \%)$. Being able to comfortably travel $(27 \pm 4 \%)$ and choosing their own style of travel (i.e., flexibility in travel) $(28 \pm 4 \%)$ are also seen as very important aspects. Travel costs are seen as an important aspect $(33 \pm 4 \%)$. By contrast, aspects regarding feeling healthy while travelling and travelling in an environmentally friendly way have relatively lower levels of importance (than the other aspects) among the residents.

How important are these aspects when choosing your mean of transport?

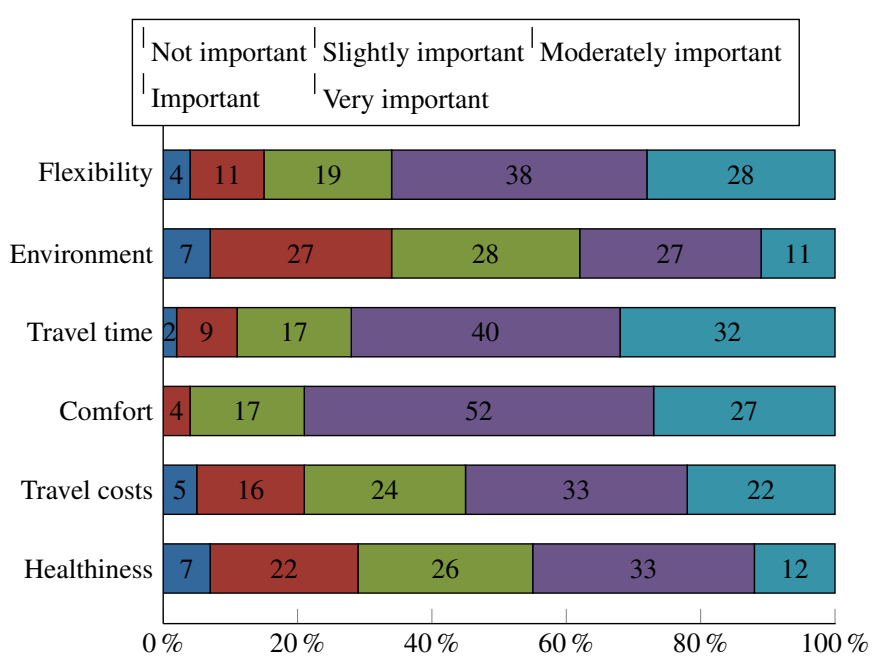

Figure 4: Residents' ranking to aspects regarding mode choice.

\subsubsection{About the likelihood of using MaaS}

We were particularly interested in finding out how likely the respondents would be willing to use MaaS when introduced in the Paleiskwartier. For that, we have presented the respondents with a mock-up (see Figure 5) containing screen-shots of a smartphone app depicting what the use of MaaS could look like as well as the following accompanying text: 


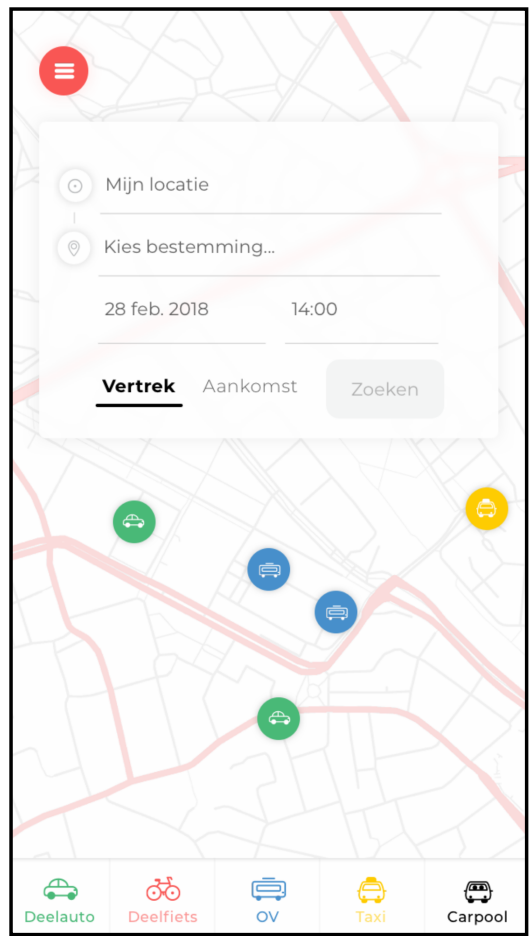

Plan

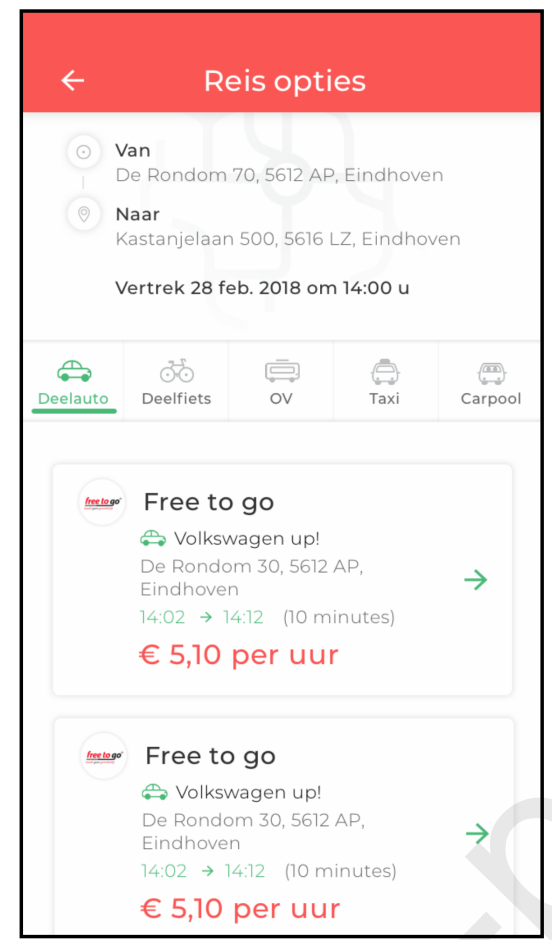

Reserve

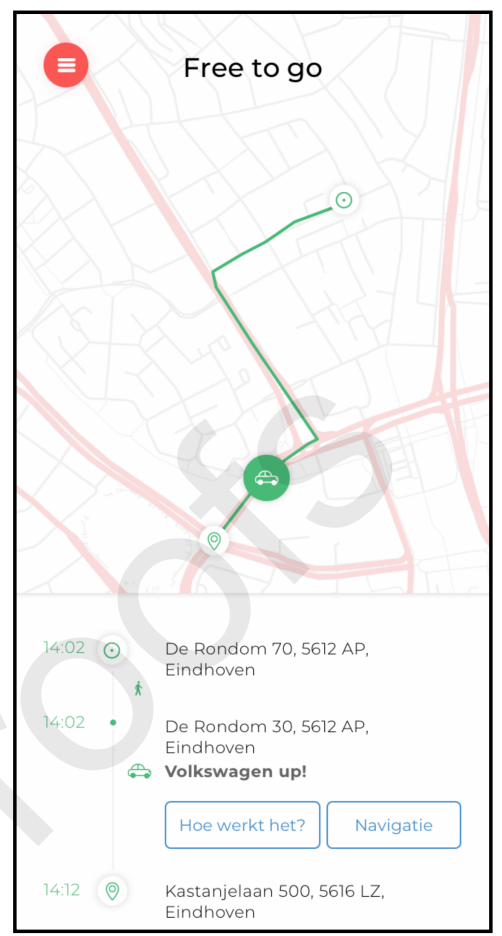

Travel

Figure 5: The MaaS mock-up used in our questionnaire.

"Soon a new mobility service will be introduced in the Paleiskwartier. This new service will allow you to access various forms of transport (such as car-sharing, bike-sharing, bus, train, and taxi) and you can ride with other residents of the Paleiskwartier. This will be done via a smartphone app, which will help you to make a good choice between different means of transport for every journey from A to B. You can then plan, book and travel within a single app. Besides, you can choose between paying per ride or having a monthly subscription."

The respondents were then subsequently asked how likely they would use MaaS in the Paleiskwartier (Figure 6).

How likely is it that you will use MaaS in the Paleiskwartier?

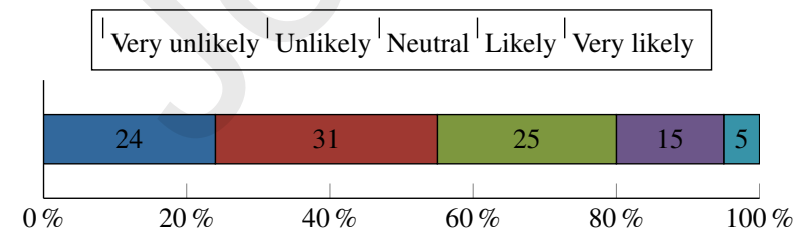

Figure 6: Frequency distribution per the likelihood of using MaaS.

Two out of 10 residents say that they would (very) likely consider using MaaS when introduced. However, approximately six out of 10 residents do not show the same enthusiasm, whereas approximately two out of 10 residents are not sure about that yet. However, it is unclear to us whether the res- idents would likely (or unlikely) consider using MaaS because they do not like the idea behind the concept of MaaS, in the first place, or because they did not like the mock-up itself (and its accompanying text) used to represent that idea. On the other hand, when asked if they would like to be informed about the introduction of MaaS in the Paleiskwartier, approximately half of the respondents $(46 \%)$ said "yes".

In order to measure respondents' attitudes towards MaaS, we asked the residents to respond to a series of statements (in terms of the extent to which they agree or disagree with them) related to using MaaS. These statements were used for psychographic segmentation to help us to decode the emotional elements of using MaaS that might otherwise seem unexplainable by solely using demographic segmentation. The distribution of observations per statement is displayed in Figure 7.

S1: I do not mind having a longer travel time for my daily trips, as long as it costs me less money.

S2: I think it is important to drive the car less due to its impact on the environment.

S3: I would not need to own a car if I had easy access to other means of transport (such as shared cars, shared bicycles, public transport). S4: Innovative mobility services (such as Uber, BlaBlaCar) make me enthusiastic.

S5: I drive mainly car because it gives me a feeling of freedom. S6: I occasionally look for alternatives for owning a car. S7: My travel pattern varies weekly. S8: I like travelling with strangers. 
To what extent do you agree or disagree with these statements?

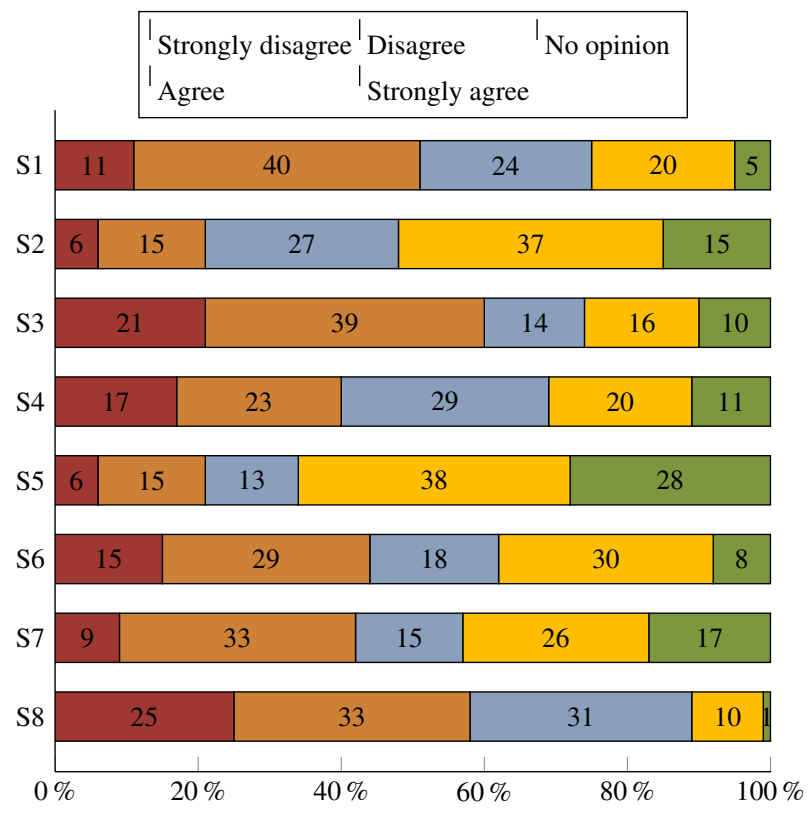

Figure 7: Residents' ranking to statements regarding MaaS.

Aligned with the results presented in Figure 4, most respondents $(51 \pm 4 \%)$ mind having a longer travel time for their daily trips, even if travel costs would be reduced (S1). Concerns with the environmental pollution due to the high amount of cars on the road (S2) are also shared by most respondents $(52 \pm 4 \%)$. Somehow not surprising, more than half $(60 \pm 4 \%)$ of respondents are reluctant in giving up their own cars in exchange for easy access to shared means of transport (S3). With respect to the enthusiasm in trying out innovative mobility services, the split in frequencies is more balanced among respondents. However, less than half $(40 \pm 4 \%)$ show no enthusiasm with Statement S4. Slightly similar to Statement S3, for the great majority of respondents $(66 \pm 4 \%)$, cars still represent freedom of movement (S5). This attachment to the importance of owning a car is also reflected on Statement S6, wherein slightly more than half of the respondents $(44 \pm 4 \%)$ declare that they do not look for alternatives to their cars. When asked if their travel pattern varies weekly, we observe here a technical tie, with approximately four out of 10 respondents agreeing or disagreeing with Statement S7. Finally, despite more than one-quarter $(31 \pm 4 \%)$ having no opinion about travelling with strangers (S8), more than half $(58 \pm 4 \%)$ actually dislike doing that.

\subsection{Bivariate analysis}

We present now some bivariate analysis of our results, wherein we seek to find any association between demographic factors, travel behaviour, travel aspects and MaaS-related statements with the likelihood of using MaaS. In our further analysis, we have merged the latter (see Figure 6) into 3 categories: unlikely, neutral, and likely.

\subsubsection{Demographics}

We analyse here whether demographic factors are associated with the likelihood of using MaaS. The demographic factors considered were: gender, age, education level, household size, and (yearly gross) household income (see Table 1 for their frequency distribution). A summary of these associations is shown in Table 3.

\begin{tabular}{|c||c|}
\hline Association of interest & $\begin{array}{c}\text { Chi-square independence test } \\
\text { or One-way ANOVA }\end{array}$ \\
\hline MaaS and gender & $\chi^{2}(2)=4.36, \mathrm{p}=0.113$ \\
\hline MaaS and age & $\mathrm{F}(2,546)=0.91, \mathrm{p}=0.404$ \\
\hline MaaS and education level & $\chi^{2}(4)=11.60, \mathrm{p}=0.021$ \\
\hline MaaS and household size & $\chi^{2}(4)=4.43, \mathrm{p}=0.351$ \\
\hline MaaS and household income & $\chi^{2}(10)=10.40, \mathrm{p}=0.407$ \\
\hline
\end{tabular}

Table 3: Association summary between demographics and the likelihood of using MaaS.

We have observed a significant $(p<0.05)$ association between education level and the likelihood of using MaaS, but we take this association with caution. As observed in Table 1, our sample was not representative of the population we are investigating. Young individuals were underrepresented and household size was inversely represented. To address these misrepresentations, we have corrected them by weighting our respondents. However, we lack information on our population of interest regarding education level and household income. It is therefore plausible that by correcting these other (probable) misrepresentations, the associations with respect to MaaS versus education level and household income could rend different results. Interestingly enough, though; the likelihood of using MaaS resulted in similar mean ages for the respondents; $\mathrm{F}(2,546)=0.91, \mathrm{p}=0.404$, which was something we did not expect given the difficulties by elderly people in using ICT technologies (Klimova and Maresova, 2016).

\subsubsection{The frequency of usage of modes of transport and route planners}

We sought then to find out whether the frequency of usage of different modes of transport (see Figure 2 for their frequency distribution) is associated with the likelihood of using MaaS. A summary of these associations is shown in Table 4.

\begin{tabular}{|c||c|}
\hline Association of interest & Chi-square independence test \\
\hline MaaS and bicycle & $\chi^{2}(8)=13.87, \mathrm{p}=0.085$ \\
\hline MaaS and car $(1)$ & $\chi^{2}(8)=23.70, \mathrm{p}=0.003$ \\
\hline MaaS and car $(2)$ & $\chi^{2}(8)=12.40, \mathrm{p}=0.134$ \\
\hline MaaS and car $(3)$ & $\chi^{2}(8)=7.42, \mathrm{p}=0.492$ \\
\hline MaaS and train & $\chi^{2}(8)=15.93, \mathrm{p}=0.043$ \\
\hline MaaS and bus & $\chi^{2}(8)=20.14, \mathrm{p}=0.010$ \\
\hline
\end{tabular}

Table 4: Association summary between frequency of usage of different modes of transport and the likelihood of using MaaS.

We highlight here contingency Table 5 between the categorical variables likelihood of using MaaS and frequency of car use (as a driver without passengers). Valuable to note that people who almost never use the car are more likely to take up MaaS. 


\begin{tabular}{|c|c|c|c|c|c|c|c|c|c|c|c|c|c|}
\hline & & \multicolumn{10}{|c|}{ Car (as a driver without passengers) } & & \\
\hline & & \multicolumn{2}{|c|}{ Almost never } & \multicolumn{2}{|c|}{ Sometimes } & \multicolumn{2}{|c|}{ Monthly } & \multicolumn{2}{|c|}{ Weekly } & \multicolumn{2}{|c|}{ Daily } & \multicolumn{2}{|c|}{ Total } \\
\hline & & $\mathrm{n}$ & $\%$ & $\mathrm{n}$ & $\%$ & $\mathrm{n}$ & $\%$ & $\mathrm{n}$ & $\%$ & $\mathrm{n}$ & $\%$ & $\mathrm{n}$ & $\%$ \\
\hline \multirow[t]{3}{*}{ MaaS likelihood } & Unlikely & 28 & $9.4 \%$ & 17 & $5.7 \%$ & 27 & $9.1 \%$ & 93 & $31.2 \%$ & 133 & $44.6 \%$ & 298 & $100.0 \%$ \\
\hline & Neutral & 12 & $9.5 \%$ & 7 & $5.6 \%$ & 16 & $12.7 \%$ & 39 & $31.0 \%$ & 52 & $41.3 \%$ & 126 & $100.0 \%$ \\
\hline & Likely & 22 & $20.8 \%$ & 10 & $9.4 \%$ & 17 & $16.0 \%$ & 32 & $30.2 \%$ & 25 & $23.6 \%$ & 106 & $100.0 \%$ \\
\hline Total & & 62 & $11.7 \%$ & 34 & $6.4 \%$ & 60 & $11.3 \%$ & 164 & $30.9 \%$ & 210 & $39.6 \%$ & 530 & $100.0 \%$ \\
\hline
\end{tabular}

Table 5: Crosstabulation frequency the likelihood of using MaaS and frequency of car use (as a driver without passengers)

In contrast, people who daily use the car (alone) are unlikely to do so. Regarding the frequency of use of public transport, we observed that people who sometimes take the bus and who regularly (monthly, at least) take the train are more likely to use MaaS. We have also observed that people who daily or weekly use route planners are more likely to take up MaaS, $\chi^{2}(8)=$ 21.03, $\mathrm{p}=0.005$.

\subsubsection{Aspects for choosing a particular mode of transport}

Next, we sought to find out whether certain aspects for choosing a particular mode of transport (see Figure 4 for their frequency distribution) are associated with the likelihood of using MaaS. A summary of these associations is shown in Table 7.

\begin{tabular}{|c||c|}
\hline Association of interest & Chi-square independence test \\
\hline MaaS and flexibility & $\chi^{2}(8)=17.06, \mathrm{p}=0.029$ \\
\hline MaaS and environment & $\chi^{2}(8)=32.05, \mathrm{p}=0.000$ \\
\hline MaaS and travel time & $\chi^{2}(8)=4.59, \mathrm{p}=0.801$ \\
\hline MaaS and comfort & $\chi^{2}(8)=8.81, \mathrm{p}=0.358$ \\
\hline MaaS and travel costs & $\chi^{2}(8)=10.90, \mathrm{p}=0.207$ \\
\hline MaaS and healthiness & $\chi^{2}(8)=44.02, \mathrm{p}=0.000$ \\
\hline
\end{tabular}

Table 7: Association summary between aspects for choosing a particular mode of transport and the likelihood of using MaaS.

Very significant associations between the likelihood of using MaaS and aspects regarding feeling healthy while travelling and travelling in an environmentally friendly way were observed. People who rate these aspects higher in the level of importance are more likely to be willing to use MaaS. Equally relevant, flexibility in travel also shows some significant association with the variable of interest. People who rate flexibility in travel as very important are less likely to take up MaaS, people who rate it as important are more likely to take up MaaS whereas those who rate it as slightly important are neutral regarding doing so.

\subsubsection{MaaS-related statements}

Finally, we sought to find out whether certain MaaS-related statements (see Figure 7 for their frequency distribution) are associated with the likelihood of using MaaS. Worth mentioning here that we have merged these statements into 3 categories: disagree, neutral, and agree, so that no more than $20 \%$ of all cells in the crosstabulation frequency table may have an expected frequency $<5$ and all expected frequencies $>1$. A summary of these associations is shown in Table 8.

\begin{tabular}{|c||c|}
\hline Association of interest & Chi-square independence test \\
\hline MaaS and S1 & $\chi^{2}(4)=25.10, \mathrm{p}=0.000$ \\
\hline MaaS and S2 & $\chi^{2}(4)=47.40, \mathrm{p}=0.000$ \\
\hline MaaS and S3 & $\chi^{2}(4)=76.26, \mathrm{p}=0.000$ \\
\hline MaaS and S4 & $\chi^{2}(4)=92.85, \mathrm{p}=0.000$ \\
\hline MaaS and S5 & $\chi^{2}(4)=4.45, \mathrm{p}=0.348$ \\
\hline MaaS and S6 & $\chi^{2}(4)=47.12, \mathrm{p}=0.000$ \\
\hline MaaS and S7 & $\chi^{2}(4)=4.48, \mathrm{p}=0.345$ \\
\hline MaaS and S8 & $\chi^{2}(4)=60.17, \mathrm{p}=0.000$ \\
\hline
\end{tabular}

Table 8: Association summary between MaaS-related statements and the likelihood of using MaaS

Here we see a clear division of opinions. In all MaaS-related statements that have a significant association with the likelihood of using MaaS, namely statements S1, S2, S3, S4, $\mathrm{S6}$, and S8, people who disagree with those statements are less likely to take up MaaS. The opposite holds true, as well. We highlight here contingency Table 6 between the likelihood of using MaaS and statement S3: I would not need to own a car if I had easy access to other means of transport (such as shared cars, shared bicycles, public transport) - which is basically the MaaS initiatives' ultimate goal. People who disagree with that statement are less likely to take up MaaS. In contrast, people who agree with it are more likely to do that.

MaaS likelihood * Statement S3 Crosstabulation

\begin{tabular}{|c|c|c|c|c|c|c|c|c|c|}
\hline & & \multicolumn{6}{|c|}{$\begin{array}{l}\text { I would not need to own a car, if I had easy access to other means of transport (such as } \\
\text { shared cars, shared bicycles, public transport) }\end{array}$} & & \\
\hline & & \multicolumn{2}{|c|}{ Disagree } & \multicolumn{2}{|c|}{ Neutral } & \multicolumn{2}{|c|}{ Agree } & \multicolumn{2}{|c|}{ Total } \\
\hline & & $\mathrm{n}$ & $\%$ & $\mathbf{n}$ & $\%$ & $\mathbf{n}$ & $\%$ & $\mathbf{n}$ & $\%$ \\
\hline \multirow{3}{*}{$\begin{array}{l}\text { MaaS } \\
\text { likelihood }\end{array}$} & Unlikely & 209 & $74.4 \%$ & 35 & $12.5 \%$ & 37 & $13.2 \%$ & 281 & $100.0 \%$ \\
\hline & Neutral & 68 & $53.1 \%$ & 18 & $14.1 \%$ & 42 & $32.8 \%$ & 128 & $100.0 \%$ \\
\hline & Likely & 29 & $28.7 \%$ & 20 & $19.8 \%$ & 52 & $51.5 \%$ & 101 & $100.0 \%$ \\
\hline Total & & 306 & $60.0 \%$ & 73 & $14.3 \%$ & 131 & $25.7 \%$ & 510 & $100.0 \%$ \\
\hline
\end{tabular}

Table 6: Crosstabulation frequency the likelihood of using MaaS and statement S3. 
We conclude here that people who do not see car ownership and its usage as very important, who regularly use public transport and who are mostly concerned with the environment and with a healthy commuting lifestyle, are more receptive to the idea of using MaaS (in the Paleiskwartier, at least). They are therefore the ideal target for campaigns that envisages introducing the idea of using MaaS. Conversely, people who daily use the car and see it as a very important asset are more reluctant to give away the convenience and comfort of their cars and take up MaaS, instead. In summary, the sole idea of MaaS as a carefree, environmentally sound alternative to make car ownership superfluous may potentially be inefficient against avid car users.

\subsection{Ordinal regression}

Before proceeding to examine the individual coefficients of our ordinal regression, we look first at the overall test of the null hypothesis. That is, we want to see whether the location coefficients for all of the variables in the model are 0. For this test, we observe the change in -2 log-likelihood when the variables are added to a model that contains only the intercept.

\begin{tabular}{lrrrr}
\multicolumn{2}{l}{ Model Fitting Information } \\
\hline Model & $\begin{array}{c}\text {-2 Log } \\
\text { Likelihood }\end{array}$ & Chi-Square & df & Sig. \\
\hline Intercept Only & 732.614 & & & \\
Final & 564.762 & 167.852 & 34 & .000 \\
\hline Link function: Logit.
\end{tabular}

Figure 8: Model fitting information.

From Figure 8, we can see that the difference between the two -2 log-likelihood values (i.e., the Chi-Square) has an observed significance level of less than 0.0005 . This means that we can reject the null hypothesis that the model without predictors is as good as the model with the predictors and our model is, therefore, statistically significant.

From the observed significance levels in Figure 9, we see that frequency of car use, the wish of travelling healthy or flexibly, the no need of owning a car (S3) or searching alternatives for it (S6), the interest for innovative mobility services (S4) and, finally, the pleasure of travelling with strangers (S8) are all related to the likelihood of using MaaS. The remaining variables do not appear to influence that likelihood. It is worth mentioning that the aspect with respect to travelling in an environmentally friendly way and the MaaS-related statement S2 showed collinearity. We dropped the former to solve this situation.

By considering all the significant (independent) variables together, we conclude, based on our ordinal regression model, that people who almost never travel by car (Car use=1) are more likely to use MaaS than people who use the car daily. People who stated that travelling healthy is slightly important (Healthiness $=2$ ) or moderately important (Healthiness $=3$ ) are less likely to use MaaS than people who believe travelling healthy is very important. In contrast, people who believe that flexibility in travel is moderately important (Flexibility=3) or important (Flexibility=4) are more likely to use MaaS than people who believe flexibility in travel is a must. Regarding the MaaS-related statements (See Figure 7), people who do not seek to get rid of their cars (even if easy access to other means of transport would be made available) $(\mathrm{S} 3=1)$ or do not seek alternatives for it $(\mathrm{S} 6=1)$, who do not like travelling with strangers $(\mathrm{S} 8=1)$, and who are either not enthusiastic about innovative mobility services ( $\mathrm{S} 4=1)$ or neutral about it $(\mathrm{S} 4=2)$ are less likely to use MaaS than people who agree with those.

\subsection{Cluster analysis}

To distinguish different personas (i.e., clusters) among Paleiskwartier residents with respect to their intention of using MaaS, we used SPSS Two-step cluster analysis. By performing hierarchical analysis first, 4 distinct clusters were revealed. Hereafter, K-means clustering $(\mathrm{k}=4)$ was conducted in order to investigate which independent variables better characterise specific cluster members. The independent variables used in our cluster analysis consists of the variables described in our univariate analysis (see Section 4.2) plus some other questions used in our survey, which their summary descriptions have deliberately been omitted due to space constraints. In total, 358 participants have been clustered into four clusters and characterised as follows:

- Cluster 1 - MaaS curious (18\%): This cluster contains respondents who have reported a high likelihood of using MaaS (score 3.8 on a 5-point Likert-type scale). A high likelihood of using MaaS is also associated with positive attitudes towards MaaS-related statements (see Figure 7), frequent use of the train, preference to use the train for different trip purposes and the lowest rate of car ownership per household ( $\bar{x}=0.57$ cars/household). Moreover, Cluster 1 members use significantly more frequent route planners than members in Clusters 2, 3 and $4, \chi^{2}=18.51(9), p=0.03$. These results are in line with theoretical implications for the interest in MaaS, meaning that frequent transit users and persons eager for using travel planning application will more likely be the early adopters of MaaS (Durand et al., 2018). Finally, Cluster 1 has the highest share of females (56.1\%) compared to other clusters and has a relatively high share of self-employed persons.

- Cluster 2 - Frequent car drivers (24\%): This cluster contains respondents who have reported a low intention to use MaaS (score 1.9 on a 5-point Likert-type scale). They are characterised by very frequent use of private car, preference to take the car for different trip purposes and having a varied travel pattern. High-income groups and males are over-represented in Cluster 2 and the share of self-employed persons is also the highest of all clusters $(17.5 \%)$. Relatively high car ownership rates $(\bar{x}=0.73$ car/household), the preference for using the private car for different trip purposes and its actual very frequent use are perceived as barriers for the intention to use MaaS, as reported by Karlsson et al. (2017). 
Figure 9: Ordinal regression model for the likelihood of using MaaS.

- Cluster 3 - Multimodal travellers (30\%): This cluster comprises of respondents who use different means of transport (car, train, and bike) in a similar way. Their reported likelihood of using MaaS is neutral (score 2.6 on a 5-point Likert-type scale) and their attitudes towards MaaS are also mostly neutral. An assumption for the ab- 
sence of the intention to use MaaS is the low score regarding the interest in innovative mobility services (Statement S4). A possible explanation for this is the large share of retired persons (i.e., respondents over 65 years) who (almost) never use a route planner application on their smartphone (holds for $25.5 \%$ of the cluster members). The lack of adroitness to use route planner applications is an important barrier for the intention to use MaaS, as reported by Karlsson et al. (2017) and Durand et al. (2018).

- Cluster 4 - Car lovers (28\%): This cluster contains respondents who have reported the lowest intention to use MaaS of all clusters (score 1.8 on a 5-point Likerttype scale). The share of respondents with a job is the largest $(77.3 \%)$, whereas the share of retirees is the lowest $(15.5 \%)$ among all clusters. The private car is used the most frequent of all clusters and car ownership rates are relatively high as well ( $\bar{x}=0.70 \mathrm{car} /$ household $)$. This, in combination with the low share of daily use of route planner applications, could potentially explain the lack of intention in using MaaS among members in this cluster.

We can conclude here that Cluster 1 can be labelled as potential MaaS users. They are characterised by having positive attitudes towards MaaS, they use the train very frequently, which is also reflected in their preference to use the train for different trip purposes; and they are also characterised by low car ownership rates. In addition, their use of route planner applications on a daily basis is the highest among all clusters. This implies that Cluster 1 could be depicted as potential early adopters of MaaS in the Paleiskwartier. In its turn, Cluster 3 could also be seen as potential MaaS users, given their likeability for 'typical MaaS aspects', such as multimodality and the search for alternatives for their private car. Given that they are mostly respondents over 65 years old of age, they mostly reported low interest in innovative mobility services and low frequency of use of route planner applications. As a result of that, they also have a certain lack of intention to use MaaS. Finally, Clusters 2 and 4 are the least potential MaaS users. This conclusion is based on their attitudes towards MaaS aspects, their low interest in innovative mobility services, their very frequent use of the car (at the cost of very infrequent use of the train) and their preference for the car for different trip purposes.

\subsection{Focus group analysis}

A focus group session consisting of 15 participants was also held to explore deeper opinions and attitude towards MaaS. These participants were selected among survey respondents who had shown interest in using the MaaS app and who had explicitly indicated to be willing to be contacted to know more about the introduction of MaaS in the Paleiskwartier. Moreover, these 15 participants were handpicked in order for the focus group demographics to be as comparable as possible to the population in the Paleiskwartier with respect to age and gender.

As described in Subsection 3.3, we first sought to find out what their views and attitudes are towards traditional modes of transport. The participants stated to prefer the train or bike for commuting, business trips and/or going out. They also showed positive attitudes towards innovative mobility concepts. A bit less than half of them do not have a car at their disposal. They indicate that they manage their trips to destinations with public transit (predominantly the train from the intercity railway station 's-Hertogenbosch) or by bike. Additionally, for destinations difficult to reach by public transit, they often use shared cars (e.g., Greenwheels) for those trips.

Most participants travelling with public transit on a daily basis indicate that they mostly use NS Extra, the travel planning application developed by Nederlandse Spoorwegen (a.k.a NS), which is the main passenger railway operator in the Netherlands. Participants also indicated that they do not normally try new apps at random, but they are willing to try out new forms of travel planning applications. Lastly, older participants seem rather reluctant to experiment with new apps, since they do not use their smartphone very frequently.

With respect to their views towards the added value of MaaS, participants were rather critical. They still do not see the added value of MaaS, compared to the wide range of shared modes (e.g. Greenwheels and OV-fiets) and transit (rail and bus) that are currently available in the Netherlands. As declared by one participant: "What is the added value of this [MaaS] application? I can already book my Greenwheels to reach my destination. I do not see any added value of this service...".

Also, the effort to plan (habitual) trips on a daily basis when using the MaaS app is mentioned as an important deterrent. As declared by another participant: "If I would use the MaaS app, I would have to use it on a daily basis. I think that would cost me a lot of time and effort since I have to look every single day which travel mode I have to take to reach my job. My private car gives me ease of use and is always available."

However, participants emphasised that they are predominantly interested in taking up MaaS to reach their destinations that are currently inaccessible by public transit, as emphasised by one participant: "I think it is a nice idea, this new mobility service, but I would only use it when I cannot reach my family in the rural areas surrounding this city. For trips within the city, I use my bike and in order to reach other cities, I take the train."

\section{Discussion}

The likelihood of using MaaS among residents is relatively low, but their curiosity about it is more promising

Based on this ex-ante evaluation, we observed relatively low levels of interest in using MaaS (approximately 20\%) among residents in the Paleiskwartier. One might wonder whether this lack of interest is due to the fact that residents dislike the idea of MaaS or they cannot fully comprehend what the MaaS concept might mean for them. It is also possible that we did not properly render what MaaS might look like, which might have resulted in the respondents being rather sceptical about seeing themselves using it. However, once the MaaS pilot is finally up and running in the Paleiskwartier, residents may have then a better understanding of what the MaaS concept could mean for them. As reported by Sochor et al. (2014), curiosity was 
also the strongest motivator for participants to join the UbiGo MaaS pilot in Göthenburg. Therefore, given that the levels of curiosity regarding the introduction of MaaS is slightly higher (46\%) among the residents, a considerable amount of residents may be interested in experimenting it, at least.

Travel behaviour and attitudes say something about interest in MaaS, demographics (apparently) not

People who regularly use public transport and have strong believes in green and healthy commuting are, very likely, strong candidates to take up MaaS in the long run. On the other hand, avid car users with considerable disregard for the environment (and, to a certain extent, to their health too) are not. Interestingly enough, we expected demographic factors to play a role in defining candidates to use MaaS, especially with respect to age. Since some ICT knowledge is required to use the MaaS application (e.g., enough skills to manipulate a smartphone), we were excepting older people to be less interested in MaaS. However, our analysis seems to show that that is not the case since we observed the same mean age for the likelihood of using MaaS in our sample. Valuable to not, although, that older people do show lack of affinity with ICT technology, as observed by their low use of route planner applications on smartphones and low interest for innovative mobility services, which use ICT technology as basis, such as Uber or BlaBlacar.

One might also argue that the proximity of the Paleiskwartier district to the central railway station for the city of 'sHertogenbosch as well as the residents preference for using the train for different trip purposes is a double-edged sword for the introduction of a MaaS pilot. In this study, we find that travel habits and attitudes towards transport modes are stronger predictors for the uptake of MaaS services than socio-economic variables (e.g., age, education level, household income). This is probably the result of the specific characteristics of the case study area and residential self-selection. This entails that households choose their residential neighbourhood based on their travel attitudes, and there is a high correlation between attitudes and built environment characteristics (van de Coevering et al., 2016). We did find residents of the Paleiskwartier area to have a relatively strong preference to commute or do social and business trips by train (see Table 2). This is particularly the case for highly educated and high-income residents. Also, this positively influences the uptake of MaaS as residents who regularly use or prefer public transport might be the first potential users of MaaS since this group is already familiar with multimodal travelling, as indicated by others (Sochor et al., 2015) (Karlsson et al., 2016). However, the familiarity with current public transport, shared modes and proximity to the central railway station might also hinder the adoption of MaaS given their familiarity with existing planning, booking and payment platforms. The focus group interviews indicated that residents who are satisfied with their existing transport possibilities were not yet convinced that MaaS would offer value added for them and enrich their satisfaction with travel.

\section{The added value of MaaS needs to be better highlighted}

Linked to the scepticism in using MaaS, participants have reported that they do not see the added value of using MaaS for their whereabouts, even though they reported positive attitudes towards innovative mobility concepts. After mentioning the benefits of MaaS, such as freedom of preferred transport option and potentially cheaper costs than owning a car, participants still do not contemplate the added value of MaaS, when compared to the wide range of shared modes and transit currently available in the Netherlands.

During the focus group session, participants emphasised that the coverage of MaaS is an important factor, though. Apart from the perspective that MaaS could ease the often challenging experience of paying for public transport in an unfamiliar area, MaaS could also enhance equity regarding accessibility. For example, MaaS could improve the accessibility of areas that are inaccessible by public transport (e.g., rural or industrial areas), which, as a result, could benefit specific societal groups that do not have access to a private car but need transportation to reach their destinations.

\section{Limitations of the research}

It is possible that our research study may not have attracted a representative subset of residents and, as a result of that, no reliable conclusions can be drawn from the observed survey data. Some groups of people may have been misrepresented. Given that the population age and household size distributions are available, we were able to compare the response distribution of those variables with the population distribution and properly correct this lack of representativeness by means of weighting adjustment. However, we have insufficient information about the population education level and yearly gross household income distributions. As a consequence, we were unable to, first, find out whether any misrepresentation exists, and, second, if so, to correct them. All things considered, the findings presented in this research study might potentially be biased and should be, therefore, cautiously taken into consideration.

\section{Future directions}

This research study reveals some key areas where further research could be directed. First, in order to get (more) people interested in taking up MaaS, it might be more fruitful focusing on specific target groups, such as employees. Employees might consider a monthly subscription fee for using MaaS as a modern alternative for an employee lease contract. At the price of owning a (lease) car, employees could consider instead getting unlimited access to public transport, taxi or a shared car according to their daily needs.

Second, the interaction between socio-economic characteristics and spatial configuration (i.e., residential self-selection) might provide greater insights about people's interest in taking up MaaS. For example, residents not owning a car might prefer to live in densely populated areas, so that several transport possibilities are widely available. These types of residents might become early adopters of MaaS pilots. Conversely, MaaS could be of greater importance for residents in rural areas, given that 
these areas are characterised by low accessibility rates of transit outside peak hours, compared to urban areas. In the rural context, MaaS could, therefore, contribute to reducing the inequity in transport possibilities for non-car owning residents, compared to existing low levels of transit or long door-to-door travel times (Geurs et al., 2018).

Next, our results show that people who are likely to use MaaS do not use the car that much. They mostly use public transport. There is, therefore, a risk that by facilitating the use of other modes, such as car-sharing and ride-sharing, MaaS may induce an adverse effect. For example, riders could very well give up public transport, and not their cars, in favour of ride-sharing trips as it has been the case for Uber and Lyft in major cities (Schaller, 2018). Valuable to note, although, that MaaS Global, the company behind the Whim app (MaaS Global Oy, 2019), has claimed that early users of the same app actually increased the number of trips taken on public transport by over $50 \%$, and the number of trips taken by private car was reduced (Wilding, 2018). If the same will be observed when the MaaS pilot takes place in the Paleiskwartier, that remains to be seen.

At last, more research is needed on potential nudging mechanisms that could be employed to stimulate individuals to act according to a specific desired behaviour. For instance, reducing the use of the private car while increasing the used of shared modes of transport. An example of such a nudging mechanism could be the use of gamification techniques (Deterding et al., 2011), wherein game-design elements are employed in non-gaming contexts. The exact effects (e.g., the reduction in parking needs) of these different nudging mechanisms on travel behaviour could then be investigated. Moreover, the combination of different rewarding schemes, such as money or in-kind gifts, with certain gamification techniques could also be interesting future research in order to observe which gamification strategies renders the best-desired effect.

\section{Conclusion}

Our research study is a comprehensive analysis of the current 'mood' of residents in the Paleiskwartier district, in the city of 's-Hertogenbosch, the Netherlands, with respect to the introduction of MaaS in their place of residence. The results of our analyses underline the continuing need to promote the introduction of MaaS even more, given the relatively low likelihood among residents in using MaaS in the long run. Nonetheless, our findings show quite some level of curiosity in, at least, trying MaaS out. Finally, the analysis presented here might help to better evaluate the chances of success when introducing MaaS in other densely populated areas by presenting which factors play an important role in the likelihood of taking up MaaS as well as which user characteristics to look for when introducing MaaS.

\section{Acknowledgements}

This study was supported by the Dutch Innovatie programma Mobiele Stad consortium and VerDuS SURF Pop Up funding (project No 438.17.174). It has also benefited from the collaboration with other consortium partners, especially the municipality of 's-Hertogenbosch, the Paleiskwartier Wijkbelangen neighbourhood association and the province of NoordBrabant.

\section{References}

van de Coevering, P., Maat, K., Kroesen, M., van Wee, B., 2016. Causal effects of built environment characteristics on travel behaviour: A longitudinal approach. European Journal of Transport and Infrastructure Research 16, 674-697.

Deterding, S., Sicart, M., Nacke, L., O'Hara, K., Dixon, D., 2011. Gamification: Using game-design elements in non-gaming contexts, in: CHI '11 Extended Abstracts on Human Factors in Computing Systems, ACM, New York, NY, USA. pp. 2425-2428. doi:http://doi.acm.org/10.1145/1979742.1979575.

Durand, A., Harms, L., Hoogendoorn-Lanser, S., Zijlstra, T., 2018. Mobilityas-a-Service and changes in travel preferences and travel behaviour: a literature review. Technical Report. KiM Netherlands Institute for Transport Policy Analysis.

Dutch Central Bureau of Statistics, 2015. Onderzoek Verplaatsingen in Nederland 2015. (Dutch) [Research on Transportation in the Netherlands]. URL: https : //www . cbs.nl/-/media/_pdf/2016/38/2016ep27 .pdf. [Online; accessed March 8, 2019].

Dutch Central Bureau of Statistics, 2019. Kerncijfers wijken en buurten 2018. (Dutch) [Key figures districts and neighborhoods 2018]. URL: https : //www.cbs.nl/nl-nl/maatwerk/2018/30/kerncijferswijken-en-buurten-2018. [Online; accessed March 8, 2019].

Geurs, K.T., Gkiotsalitis, K., Fioreze, T., Visser, G., Veenstra, M., 2018. The potential of a Mobility-as-a-Service platform in a depopulating area in the Netherlands: An exploration of small and big data, in: Franklin, R.S., Leeuwen, E.S.V., Paez, A. (Eds.), Population Loss: The Role of Transportation and Other Issues. Academic Press. volume 2 of Advances in Transport Policy and Planning, pp. 57 - 79. doi:https://doi.org/10.1016/bs.atpp.2018.09.001.

Hietanen, S., 2014. Mobility as a Service - The new transport model? ITS \& Transport Management Supplement. Eurotransport 12, 2-4.

Hoogendoorn-Lanser, S., Schaap, N.T., OldeKalter, M.J., 2015. The Netherlands Mobility Panel: An innovative design approach for web-based longitudinal travel data collection. Transportation Research Procedia 11, 311 329. doi:https://doi.org/10.1016/j.trpro.2015.12.027.

IMS, 2019. Het Innovatieprogramma Mobiele Stad. URL: http://www .mobiele-stad.nl. [Online; accessed March 8, 2019].

Jittrapirom, P., Caiati, V., Feneri, A.M., Ebrahimigharehbaghi, S., Alonso González, M.J., Narayan, J., 2017. Mobility as a service: A critical review of definitions, assessments of schemes, and key challenges. Urban planning 2, 13 - 25. doi:http://doi.org/10.17645/up.v2i2.931.

Kamargianni, M., Li, W., Matyas, M., Schäfer, A., 2016. A critical review of new mobility services for urban transport. Transportation Research Procedia 14, 3294-3303.

Kamargianni, M., Matyas, M., Li, W., Schäfer, A., 2015. Feasibility Study for Mobility as a Service concept in London. Technical Report. UCL Energy Institute.

Karlsson, I.M., Sochor, J., Strömberg, H., 2016. Developing the service in mobility as a service: Experiences from a field trial of an innovative travel brokerage. Transportation Research Procedia 14, 3265 - 3273. doi:https://doi.org/10.1016/j.trpro.2016.05.273. Transport Research Arena TRA2016.

Karlsson, M., Sochor, J.L., Aapaoja, A., Eckhardt, J., König, D., 2017. Deliverable 4: Impact Assessement. MAASiFiE project funded by CEDR. Technical Report. Chalmers Publication Library.

Klimova, B., Maresova, P., 2016. Elderly people and their attitude towards mobile phones and their applications - a review study, in: Park, J.J.J.H., Jin, H., Jeong, Y.S., Khan, M.K. (Eds.), Advanced Multimedia and Ubiquitous Engineering, Springer Singapore, Singapore. pp. 31-36.

Kokalitcheva, K., 2016. Uber now has 40 million monthly riders worldwide, in: Leaf, C. (Ed.), Connected Logistics. Fortune Media IP limited. URL: http://fortune.com/2016/10/20/uber-app-riders/. [Online; accessed March 8, 2019]. 
MaaS Global Oy, 2019. Whim - All transport in 1 App.

URL: https://whimapp. com. [Online; accessed March 8, 2019].

Schaller, B., 2018. The New Automobility: Lyft, Uber and the Future of American Cities. Technical Report. Schaller consulting. URL: http://www. schallerconsult.com/rideservices/automobility. pdf.

Smith, G., Sochor, J., Karlsson, I.M., 2018. Mobility as a service: Development scenarios and implications for public transport. Research in Transportation Economics 69, 592 - 599. doi:https://doi.org/10.1016/j.retrec.2018.04.001.

Sochor, J., Arby, H., Karlsson, M., Sarasini, S., 2017. A topological approach to Mobility as a Service: A proposed tool for understanding requirements and effects, and for aiding the integration of societal goals, in: 1st International Conference on Mobility as a Service (ICOMaaS), Tampere, Finland, pp. 187-201.

Sochor, J.L., Strömberg, H., Karlsson, M., 2014. Travelers motives for adopting a new, innovative travel service: Insights from the UbiGo field operational test in Göthenburg, Sweden, in: 21st World Congress on Intelligent Transport Systems, Detroit, September 7-11, 2014.

Sochor, J.L., Strömberg, H., Karlsson, M., 2015. An innovative mobility service to facilitate changes in travel behavior and mode choice, in: 22nd World Congress on Intelligent Transport Systems, Bordeaux, October 5-9, 2015.

Strömberg, H., Karlsson, I.C.M., Sochor, J., 2018. Inviting travelers to the smorgasbord of sustainable urban transport: evidence from a MaaS field trial. Transportation 45, 1655-1670. doi:http://doi.org/10.1007/s11116-0189946-8.

Wilding, M., 2018. Private companies want to replace public transport. Should we let them?, in: Viner, K. (Ed.), Guardian Cities. Guardian Media Group. URL: https://www.theguardian.com/cities/2018/mar/29/publictransport-transit-private-companies-citymapper-uber-whimsmart-buses. [Online; accessed March 8, 2019]. 